\title{
CERRABA LOS OJOS PARA VIVIR. EL TEMA DEL DOLOR DEL DESTIERRO EN TEXTOS AUTOBIOGRÁFICOS DE HÉCTOR TIZÓN
}

\author{
Cerraba los ojos para vivir. The theme of the pain of exile in autobiographical texts \\ of Héctor Tizón
}

\author{
Alejandra Liñán* \\ Universidad Nacional del Nordeste \\ alejandra.linan@comunidad.unne.edu.ar
}

\author{
Palabras clave \\ exilio; \\ clásico; \\ literatura comparada; \\ apropiación; \\ Héctor Tizón
}

\section{Resumen}

El propósito de este artículo es analizar y comprender la relación que se establece entre el tema clásico del viaje de exilio y la producción literaria del escritor argentino Héctor Tizón y se centra en los tópicos del dolor de la partida y del sentimiento de pérdida de la patria, tematizados en algunos capítulos del libro No es posible callar (2004). Entre las formas de emergencia de los clásicos en estos textos autobiográficos de Héctor Tizón, seleccionamos la asimilación de Ovidio como paradigma del dolor del exilio, con la particularidad de que, en su recepción, el sentido ha sido mediado por otro autor; así también, la figura de Odiseo, aportada al diálogo intertextual por el poema Ulysses de A. L. Tennyson. El enfoque teórico-metodológico se enmarca en la literatura comparada y recurre al concepto de transtextualidad (Genette, 1989), que fundamenta el tramado de las relaciones entre los diferentes textos. Asimismo, desde el punto de vista de la recepción clásica, algunos conceptos operativos, como apropiación y diálogo (Hardwick, 2003), contribuyen a que el trabajo crítico avance en la explicación de las nuevas significaciones producidas en la recepción creativa de nuestro autor.

\begin{abstract}
The purpose of this article is to analyze and interpret the relationship established between the classic theme of the exile trip and the literary production of the Argentine writer Héctor Tizón, focused on the topics of the pain of the departure and the feeling of longing for the lost homeland, themed in some chapters of the book No es posible callar (2004). Among the emergence forms of the classics in these autobiographical texts by Héctor Tizón, we select the assimilation of Ovid as a paradigm of the pain of exile, with the particularity that, in its reception, the meaning has been mediated by another author; so also the figure of Odysseus, included in the intertextual dialogue by the poem Ulysses by A. L. Tennyson. The theoretical-methodological frame is the comparative literature and takes the concept of transtextuality (Genette, 1989), which bases the relationships between the different texts. Also, from the point of view of classical reception, some operative concepts, such as appropriation and dialogue (Hardwick, 2003), contribute to the critical work advancing in the explanation of the new meanings produced in the creative reception of our author.
\end{abstract}




\section{Cerraba los ojos para vivir. El tema del dolor del destierro en textos autobiográficos de Héctor Tizón ${ }^{1}$}

El tema del viaje es una presencia constante en la obra narrativa, ensayística y autobiográfica del escritor argentino Héctor Tizón (1929-2012). Su insistencia se asocia tanto a hechos vividos como a razones ficcionales y literarias.

En gran medida, las variaciones en su obra pueden ser vinculadas a las vicisitudes de su vida, de las cuales la experiencia del destierro por la dictadura militar, que se impuso en la Argentina entre 1976 a 1983, ha sido la más crítica. Frente a la crisis existencial e identitaria por abandonar forzosamente todo lo propio y tener que adaptarse a una nueva cultura, para los escritores como Tizón, "cerrar los ojos para vivir" constituyó una imagen representativa del dolor del exilio.

El propósito de este artículo es analizar y comprender la relación que se establece entre el tema clásico y la producción literaria de Héctor Tizón, particularmente en cuanto al viaje de exilio y a los tópicos del dolor de la partida y del sentimiento de pérdida de la patria, presentes en el libro No es posible callar (2004).

Hemos analizado su recurrencia como parte de una indagación, más amplia, ${ }^{2}$ en la apropiación creativa de la tradición clásica por el escritor Héctor Tizón, que estimamos relevante en su obra, en cuanto a la vinculación con preocupaciones del ser humano en todas las épocas, en el marco del contexto socio cultural argentino y latinoamericano, en diferentes momentos de su historia reciente.

Entre las formas de emergencia de los clásicos en los textos de Héctor Tizón, seleccionamos la asimilación de Ovidio como paradigma del dolor del exilio, con la particularidad de que, en su recepción, el sentido ha sido mediado por la escritura de otro autor, el rumano Vintila Horia, quien había creado en su novela (Dios nació en el exilio, de 1960) un diario de Ovidio desterrado. Otra de las voces que complejizan el diálogo intertextual es la del poema Ulysses de A. L. Tennyson, que trae al texto tizoniano la figura de Odiseo viajero, resistente y curioso, diferente del otro Odiseo, el héroe que sufre añorando la "dulce patria", en la isla de Calipso (Homero, Od. 5) y entre los feacios (9, 34-35).

El análisis de los elementos comunes y de las diferencias, reveladoras de las variadas significaciones configuradas en cada contexto, aporta a la comprensión de la apropiación del tema clásico en la obra tizoniana, particularmente en sus textos de carácter autobiográfico.

En su obra narrativa y ensayística se manifiesta sostenidamente el tópico del viaje como metáfora de la vida. La insistencia en enunciados como "el hombre que vino de...", "el hombre que llegó a..." o "el hombre que se va o escapa", se cristaliza en la imagen del viajero -en fuga, por exilio

1. Una primera aproximación al tema de este artículo fue leída, no publicada, en el XXV Simposio Nacional de Estudios Clásicos y I Congreso Internacional sobre el Mundo Clásico, CABA, 2018.

2. Ha constituido el objeto de investigación de mi tesis de Doctorado en Letras, titulada Mitos y motivos griegos en la narrativa de Héctor Tizón, aprobada en la Facultad de Humanidades de la UNNE, en 2020. 
o por desesperación, o migrante, en busca de una nueva oportunidad, que arriba a sitios conocidos o desconocidos- y en un recorrido.

El viaje comienza como huida o como expulsión, por diferentes causas entramadas con los personajes, ámbitos, tiempos y propuestas de cada novela; sigue en la errancia, el vagabundeo o el recorrido de búsqueda de sí mismo; y, cuando el protagonista es afortunado, concluye en regreso o reconocimiento, como en La belleza del mundo (2004). Cuando no puede reencontrarse, solo sigue existiendo para perderse y olvidarse de sí mismo, tal como ocurre en "El hombre que vino del río", incluido en Memorial de la Puna (2012).

El destierro, la separación de la tierra natal, ha sido una preocupación dominante. Aunque su narrativa no siempre exhiba una intertextualidad explícita con la Odisea homérica, ${ }^{3}$ el viaje y el viajero, los desplazamientos, las partidas, recorridos y llegadas, se vinculan frecuentemente con el periplo clásico.

\section{Enfoque teórico-metodológico}

En cuanto al enfoque teórico-metodológico, la literatura comparada nos proporciona un marco amplio para el diálogo de textos de diferentes épocas y culturas, y nos permite diseñar y desplegar redes de relaciones.

El concepto de transtextualidad (Genette, 1989) fundamenta el tramado de las relaciones entre los diferentes textos, para profundizar en la búsqueda hermenéutica más allá de la mera comprobación del acontecimiento de la cita o de la alusión a otro/s texto/s o autor/es.

Asimismo, desde el punto de vista de la recepción clásica, algunos conceptos operativos, como apropiación y diálogo (Hardwick, 2003, p. 9), contribuyen a que el trabajo crítico avance en la explicación de las nuevas significaciones producidas en la recepción creativa de nuestro autor.

Charles Martindale (2007) ha considerado que la recepción ha dado nuevo sentido a términos usuales tales como "tradición", "legado" e "influencia" y otros. La etimología de tradition (del latín tradere) sugiere la transmisión del material del pasado hacia el presente. Reception, por contraste, al menos en el modelo de la escuela de Constanza,

opera con una temporalidad diferente, involucrando la activa participación de los lectores (incluso lectores que son ellos mismos artistas creativos) en un proceso bidireccional, tanto hacia atrás como hacia adelante, en el cual el presente y el pasado están en diálogo uno con otro. (Martindale, 2007, p. 298; la versión en castellano es nuestra)

Por consiguiente, cuando los textos son leídos en nuevas situaciones, tienen nuevos sentidos. Este es uno de los principales presupuestos que orienta nuestro análisis de la apropiación de motivos

3. Esta intertextualidad es evidente en Fuego en Casabindo (1969), El cantar del profeta y el bandido (1972) y La belleza del mundo (2004). 
clásicos en la producción literaria de Héctor Tizón, como una nueva lectura que el creador construye en diálogo con aquellos.

Ya W. B. Stanford, en su estudio clásico sobre el tema de Ulises, en el cual se propuso examinar la tradición del mito homérico en la literatura europea, no adoptó una perspectiva tradicional de atribución a "influencias", sino que tomó en cuenta el trabajo del creador artístico y los intereses personales, ideológicos y estéticos de los escritores que van adaptando un motivo antiguo en diferentes contextos (2013, p. 23-27).

Stanford también advirtió que la apropiación de un material tradicional, tal como el motivo del viaje de Odiseo, suele convertirse en un asunto de autoidentificación, en una suerte de "empatía imaginaria": "Para el escritor puede ser un medio de autodescubrimiento, de autoestímulo y autorrealización” (2013, p. 25-26).

Héctor Tizón, como escritor latinoamericano, ha heredado la biblioteca aportada por la tradición europea, que incluye la clásica, a través de la formación escolar y académica y por sus lecturas de otros autores que se hicieron cargo de ella y que lo precedieron.

\section{Breve contextualización de la obra de Héctor Tizón en la literatura argentina}

Para ubicar el período en que Tizón comienza a producir su obra literaria, recurrimos al fijado por M. T. Gramuglio (2002), desde los cambios producidos partir de 1961, cuando determinados autores argentinos empiezan a ser conocidos internacionalmente y a producir obras novedosas, junto con "el cambio de situación de la literatura latinoamericana promovido por el boom", en que "las realizaciones literarias y artísticas hacia fines de la década buscaron fusionar vanguardia estética y vanguardia política" (2014, p. 37-38).

Desde nuestro punto de vista, por el carácter particular de su obra, puesto que los avatares de su vida fueron incidiendo en su proyecto estético, cabe dividir su trayectoria literaria en tres etapas: una primera, desde fines de los años 50 hasta 1976, como parte de una generación de escritores que creó obras literarias singulares con fuerte presencia en el campo cultural argentino; la segunda, en la que experimenta el exilio desde 1976 a 1982, cuya influencia continúa en los años siguientes; y la última, desde fines del siglo XX hasta su muerte en 2012, en la cual se podría considerar un proceso de regreso a las fuentes y de autoreconocimiento, manifestado en el examen de su itinerario, un recuento por medio del cual fue construyendo una autofiguración de su trayectoria de escritor.

En las novelas publicadas después del último gobierno militar, la experiencia del exilio provocó cambios profundos en Tizón. Beatriz Sarlo, que lo ubica entre los autores de la narrativa de los diez años que van desde el'76 al '86 (2014 [1987], p. 67-68), ayuda a comprender la narrativa de aquellos tiempos difíciles, que en este escritor abarca tanto su época del destierro como sus publicaciones posteriores, las del período democrático. 
La propuesta renovadora de Héctor Tizón, en consonancia con la de algunos otros escritores jujeños, ${ }^{4}$ revela una nueva concepción del regionalismo. Sus ficciones, afirma Adrián Massei:

se anclan en un contexto geográfico y humano específico -el de la puna-, del que Tizón pretende erigirse como cronicador y para lo cual procede a una meticulosa reelaboración del regionalismo argentino que no se da en otros escritores contemporáneos a él, aun en aquéllos que tienen un origen provinciano. (1998, p. 34)

Esto ha provocado a la crítica literaria argentina a buscar un lugar especial para nuestro autor, que comparte con otros escritores una búsqueda artística centrada en la relación con sus regiones de pertenencia, por nacimiento o por adopción, como Juan José Saer y Daniel Moyano.

En este sentido, también Sarlo, en una reseña sobre La mujer de Strasser, distinguió la originalidad de su obra:

Tizón había trazado la línea original de un regionalismo libre de pintoresquismo, de paisajismo y de folklore. Tizón trabajó como nadie el entramado de mitos provincianos con mitos universales. (...) Al trabajar con mitos que, a través de los siglos, han dejado de ser mediterráneos para volverse centrales a la tradición de Occidente, Tizón pone a la literatura de su provincia en una dimensión no regionalista, sin perder nunca la materia figurativa y lingǘstica de ese espacio cultural que no es el del Río de la Plata. (2007, p. 427)

Finalmente, a Héctor Tizón es necesario situarlo en una tendencia de alcances continentales, en una segunda etapa de la renovación en la literatura latinoamericana iniciada por autores como Juan Rulfo, entre los escritores que trabajaron un efecto de oralidad ${ }^{5}$ en sus narrativas.

\section{El viaje de exilio}

El viaje de exilio ha signado, por experiencia vital y por elaboración literaria, la poética de este escritor, en particular, desde que volviera a escribir en España, después de una penosa etapa de adaptación.

Tanto la partida y el destierro como el periplo de Odiseo y las diferentes instancias del viaje clásico son motivos frecuentes de reflexión en sus memorias y ensayos, principalmente en No es posible callar (Tizón, 2004c, p. 113-127) y El resplandor de la hoguera (Tizón, 2008, p. 15, 36 y 88), así como en varias entrevistas.

El motivo clásico del viaje es una constante en su producción literaria y una de las variantes en que se manifiesta es la recurrencia temática de los tópicos del dolor de la partida y del sentimiento de pérdida de la patria.

4. Por ejemplo, los agrupados en torno a la revista literaria Tarja, en la cual colaboró Héctor Tizón. La revista irrumpió, desde 1955, en Jujuy y el NOA, con propuestas poéticas opuestas al color local y al folklorismo.

5. El desarrollo de la ubicación de la literatura de Héctor Tizón en el contexto argentino y latinoamericano excede los objetivos de esta breve sección. Para el planteo y análisis del efecto de oralidad en la narrativa de autores como J. Guimarâes Rosa, J. Rulfo, J. M. Arguedas y A. Roa Bastos (cfr. Carlos Pacheco, 1992 y 1996). 
Como adelantamos más arriba, los movimientos de partida y llegada son característicos en los personajes de la narrativa tizoniana y alcanzan preeminencia en la segunda etapa de su obra literaria, en la cual el viaje deviene un motivo central tanto en la temática como en la estructura del relato. De diferentes modos y con recorridos disímiles, en cada una los personajes principales se desplazan, ya sea en una huida (El hombre que llegó a un pueblo, 1998), una migración para encontrar un lugar en el mundo (Luz de las crueles provincias, 1995), un vagabundeo (Extraño y pálido fulgor, 1999), una vida en el destierro (El viejo soldado, 2002).

Aunque la Odisea es una referencia recurrente en su obra, con respecto al viaje y también al destierro, las novelas de este período no están ligadas al texto homérico, ni las referencias a los motivos antiguos o a los autores grecolatinos adquieren importancia en la estructura ni en el sentido ni en el mundo representado.

Ahora bien, los tópicos relativos al exilio provenientes de la antigüedad están presentes en otros textos, los autobiográficos publicados sobre todo a partir del año 2000, que refieren a ese tiempo aciago que signó su vida desde el momento de la salida forzada del país y de su casa. Especialmente, se condensan en los capítulos "Exilio"6 y "Ahora cerraremos los ojos cuando nos dé la gana" (2004c, p. 115-123), incluidos en la tercera parte del libro No es posible callar.

Una de las instancias emblemáticas de representación ficcional de la partida al destierro, en su obra, ha sido la larga despedida del hombre que huye antes de irse definitivamente, en La casa y el viento: ${ }^{7}$

Cuando decidí partir, dejar lo que amaba y era mío, sabía que era para siempre, que no iba a ser una simple ausencia sino un acto irreparable, penoso y vergonzante, como una fuga. En realidad todas mis partidas fueron fugas. Creo que es la única forma de irse. (2001, p. 15)

Ese rodeo, en lugar de concretar rápidamente el trámite doloroso, lo demora en el afán de retener todo aquello que puede llevarse consigo de ese, su propio mundo, familiar y a la vez despiadado con sus habitantes, que ahora está abandonando. Se "arranca” para separarse de su tierra y dejarla, pero en ese largo vagabundeo de despedida procura llevarse todo lo que constituye su mundo, atesorarlo en la memoria, ya que está por perderlo en el plano material y en cuanto a contacto humano.

Edward Said, exiliado él también, ha caracterizado nuestra contemporaneidad como una época signada por las expatriaciones y "el exilio como castigo político contemporáneo" (2005, p. 104). $\mathrm{Ha}$ analizado la actitud del exiliado tanto en los escritores individualmente como en los grupos de refugiados, y rescata a aquellos poetas y escritores "que confirieron dignidad a una condición orientada por ley a negar la dignidad: a negar la identidad de las personas" (p. 104). Para este pensador, el "pathos del exilio reside en la pérdida de contacto con la firmeza y la satisfacción de la tierra: volver a casa es de todo punto imposible" (p. 108).

6. Texto publicado inicialmente en el libro Decíamos ayer, compilado por Aulicino y Zubieta (2002).

7. Terminó de escribirla en febrero de 1982, pero fue publicada en 1984. 
Este sufrimiento por la separación de lo propio y familiar que hace vacilar la identidad se verá plasmado en la obra de Tizón. Como tópico tiene una extensa tradición literaria desde la Antigüedad, de la cual se destacan los conocidos ejemplos de escritores exiliados que forman parte de la historia literaria de Grecia, "desde los tempranos poetas líricos Alcmán, Arquíloco y Safo, pasando por Tucídides hasta Diógenes el Cínico”(Withmarsh, 2001, p. 275).

Con las múltiples posibilidades de dramatización y puesta en escena del "yo", se fue configurando una topología literaria del exilio. Al respecto es ejemplar el caso de Ovidio, quien la manipuló con la máxima autoconciencia (Williams, citado en Whitmarsh, 2001, p. 275).

En su capítulo sobre exilio y literatura del libro Múltiples moradas, el comparatista español Claudio Guillén planteó dos actitudes básicas ante el destierro proporcionadas por la Antigüedad: "una polaridad amplia y pronunciada, entre dos principios valorativos opuestos, que podríamos llamar ovidiano y plutarqueo" (1998, p. 46). Para delinear el primer talante frente al exilio, se basa en la propuesta de Plutarco en la epístola De exilio, donde refutaba a quienes habían deplorado los males del destierro. Así explica que, para el ser humano, el trasladarse "de lugar y de sociedad" comporta la posibilidad de abrirse a las dimensiones cósmicas de la naturaleza y de "descubrir o de comprender más profundamente todo cuanto tiene en común con los demás hombres, uniéndose a ellos más allá de las fronteras de lo local y de lo particular" (1998, p. 33).

En cuanto al otro extremo de la polaridad, Guillén valoró a Ovidio como modelo para la tradición poética occidental:

Ovidio será a lo largo de los siglos el arquetipo de un segundo talante, que, dicho sea con toda sencillez, vendrá a ser lo opuesto de la actitud cínico-estoica: una sensibilidad afligida, negativa, centrada en la protesta, la nostalgia y la lamentación. (1998, p. 36)

El tópico literario del dolor del destierro fue fijado por Ovidio en Tristezas. Sus elegías subrayan el sufrimiento, provocado por su relegatio ${ }^{8}$ ordenada por Augusto, y el lamento por no poder dejar de pensar, soñar, sentir siempre el anhelo de estar en su patria. La poesía obraba como consuelo y, al mismo tiempo, auxiliaba al poeta para lograr la vuelta a Roma, como lo expresa en $\operatorname{Tr}$. 5.1.45-48:

Cantaré lo que él mismo apruebe, con tal de que, aliviado algo de mi castigo pueda huir de esta barbarie y de los crueles getas.

Entre tanto, ¿qué libritos puedo componer, sino de tristezas?

Esa flauta es adecuada para mis funerales. ${ }^{9}$

Y más adelante señala los ejemplos de aves míticas que tuvieron el lamento (la poesía) como remedio de dolores:

8. El destierro de Ovidio en Tomis (en la actual Rumania) abarcó desde el 8 d.C. hasta su muerte en 17 d.C. Los cinco libros de elegías que componen Tristia fueron escritos en ese período.

9. "quod probet ipse, canam, poenae modo parte levata / barbariam rigidos effugiamque Getas. / interea nostri quid agant, nisi triste, libelli? / tibia funeribus convenit ista meis". Las citas de los versos ovidianos en latín siguen la edición de Arthur Leslie Wheeler (1939), consultada en Perseus Digital Library. Las versiones en castellano corresponden a: Ovidio (2010) Tristezas - Pónticas (edición de Eulogio Baeza Angulo). 
De algo sirve aliviar los funestos males por medio de las palabras: por esto se quejan Procne y Alción. ${ }^{10}$

W. B. Stanford en The Ulysses Theme (1954) tomó en consideración a Ovidio como fuente de la tradición clásica sobre Ulises para los escritores medievales y modernos (2013, p. 180-184). Expuso que la visión ovidiana sobre el héroe homérico toma otro cariz después de que se viera obligado a alejarse de Roma, puesto que encontró "un símbolo de su propio destino en las descripciones de Homero del héroe errante". Otros poetas más tempranos encontraron "consuelo y fuerza en el valor y en la resistencia de Ulises. E1 tono de Ovidio es más quejumbroso” (p. 183).

Lo que Stanford rescata como notable para la tradición general es que "Ovidio proporciona en la literatura latina el ejemplo más llamativo de autoidentificación de un poeta con el itacense exiliado" (p. 184). La apropiación de la figura de Odiseo por parte de Ovidio permanece en el plano personal, a diferencia de la relectura de los estoicos, que apunta al plano moral. Así leemos en Tr. 3.11.61-62 su lamento por el dolor sufrido, intensificado por la analogía de la ira de Poseidón contra Odiseo con la de Augusto (nombrado como Júpiter) contra él: "Créeme, si Ulises se comparase conmigo, / la cólera de Neptuno fue más leve que la de Júpiter"; ${ }^{11}$ o en $\operatorname{Tr}$. 1.2.9-12, donde el poeta apela también a la comparación con Ulises para mostrarse quejoso de no tener una Minerva que lo proteja de un dios iracundo. ${ }^{12}$

En Tristezas es permanente el recuerdo de Roma, que trae las frecuentes comparaciones entre la belleza de la ciudad de la nostalgia y la dura realidad de Tomis, subrayada por la hipérbole poética, como puede observarse en $\operatorname{Tr}$. 3.2.19-22, cuando muestra el dolor, una vez acabados los trabajos del viaje y habiendo llegado a la tierra de castigo:

nada me consuela sino llorar, y es más abundante la lluvia

de mis ojos que el agua que mana de la nieve primaveral.

Me viene a la memoria Roma, mi casa y el deseo de aquellos lugares, y todo lo que queda de mí en la ciudad perdida. ${ }^{13}$

La imagen de la tierra de uno como "dulce" nos remite también al tópico de Odiseo sufriente, quien se deshacía en lamentos en la isla de Calipso, de la que ansiaba partir (Od. 5.151-158), y luego, ante el rey de los feacios, Alcínoo, expresó que 'nada existe más dulce que la propia patria y los padres'

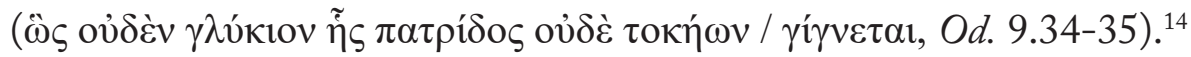

10. "est aliquid, fatale malum per verba levare. / hoc quendam Procnen Halcyonenque facit", Tr. 5.1.59-60.

11. "crede mihi, si sit nobis collatus Ulixes, / Neptuni minor est quam Iovis ira fuit."

12. "saepe ferox cautum petiit Neptunus Ulixen; / eripuit patruo saepe Minerva suo. / et nobis aliquod, quamvis distamus ab illis, / quis vetat irato numen adesse deo?" ('A menudo el feroz Neptuno atacó al prudente Ulises; / Minerva frecuentemente lo arrancó de su tío paterno. / ¿Y a mí, aunque disto de aquéllos, quién impide / que una divinidad me proteja de un dios iracundo?').

13. "nil nisi flere libet, nec nostro parcior imber / lumine, de verna quam nive manat aqua. / Roma domusque subit desideriumque locorum, / quicquid et amissa restat in urbe mei".

14. Cfr. Trabajos críticos que han planteado el tópico del exilio en el análisis de la obra homérica: Zecchin de Fasano (2008), Perry (2010). 
Ovidio, en la elegía que rememora la última noche en Roma, reunió en una misma imagen dulzura, amor y patria: "blando patriae retinebar amore" ('el dulce amor a la patria me retenía', $T r$. 1.3.49), cuando estaba finalizando la noche anterior a la forzosa partida y él demoraba ese momento. También recuerda lo que había sido dulce para él, puesto que ya estaban lejos su patria y su esposa: "y cuanto después de estas dos cosas me fue dulce", ${ }^{15}$ en Libro III.4b.

El destierro de Ovidio fue una referencia común para un grupo de escritores argentinos exiliados ${ }^{16}$ en España, para quienes esa angustia por la lejanía de la patria y de la cultura de pertenencia era un sentimiento compartido, y tan dominante que, a algunos, durante un tiempo, les bloqueó la posibilidad de escribir. Esta circunstancia es comentada por Silvina Friera, quien cita las palabras de nuestro autor en "Cerrar los ojos para vivir", reseña periodística de una mesa redonda en homenaje a los escritores víctimas de la represión de estado (2-5-2002).

Héctor Tizón empleó esa imagen en "Ahora cerraremos los ojos cuando nos dé la gana" (2004c, p. 121-123). Se trata de un motivo trasegado ${ }^{17}$ de uno a otro escritor, por la mediación de la novela Dios nació en el exilio de Vintila Horia, a quien nuestro autor conoció en España.

Esta identificación de un desterrado con otros anteriores, proporcionada por la formación literaria y cultural, es un rasgo que analizamos por su relevancia temática en la obra tizoniana.

Héctor Tizón no cita textos de Ovidio en las novelas. Las publicaciones que lo tematizan son sus memorias, y también algunas entrevistas, donde ha tomado forma esa imagen -ovidiana a través de otro autor- de "cierro los ojos para vivir", expresión que lo tocó hondamente por la novela ${ }^{18}$ de Vintila Horia, publicada en 1960, pero leída cuando vivía en España, siendo él mismo un exiliado doliente.

El autor rumano construyó a Ovidio como protagonista, que escribe su diario en su destierro en Tomis. El epígrafe elegido para encabezar la novela es un verso de la elegía Tr. 3.7.48: "Caesar in hoc potuit iuris habere nihil” ('contra éste el César no pudo tener ningún derecho'), en referencia a su talento, mencionado en el verso precedente. Es decir que la cita inicial resalta el tratamiento de la problemática del exiliado frente al poder que lo arrojó fuera de su patria y para quien, ante la pérdida de todo lo que conformaba la cultura propia, la creación poética es lo único que no pueden arrebatarle mientras permanezca vivo.

El protagonista expresa sus pesares y dudas en primera persona:

Lo curioso, en medio de mi desesperación, es que no puedo acostumbrarme a la idea del cambio. Hace unos diez días que estoy aquí; salí de Roma hace tres meses, pero estoy en Roma, y me parece que bastaría prolongar un poco más un pensamiento o una imagen, para cambiar de lugar e integrarme de nuevo a mi ritmo y a mi espacio habituales. En este momento, al escribir estas líneas, me siento invadido por una duda horrible. Roma está lejos, en el otro extremo de la tierra y ningún pensamiento es capaz de hacerme cambiar de lugar. (1961, p. 20-21)

15. "at longe patria est, longe carissima coniunx, / quicquid et haec nobis post duo dulce fuit" (Tr. 3.4b.53-54).

16. Junto a Héctor Tizón, Daniel Moyano y Antonio Di Benedetto, entre otros.

17. Concepto empleado por Rubén Florio (1996) en "De Virgilio a Sábato: trasiego de catábasis".

18. Es la frase con la que se inicia. 
Vintila Horia recreó la vida de Ovidio fuera de su patria, expulsado de todo lo que le interesaba y ocupado en la escritura de un diario que abarca ocho años, en base a los datos que le proporcionaban las obras ovidianas (Tristia y Epistulae ex Ponto) producidas en aquel amargo período.

\section{Tristezas del exilio}

El pathos causado por la situación de destierro, en el caso de Héctor Tizón, se manifiesta recurrentemente en el sentido de pérdida y, particularmente, en la preocupación por la pérdida de la identidad, expresada en los rasgos propios, en el mundo personal y en la cultura de pertenencia, que teme se desdibujen con la asimilación a una nueva sociedad y una cultura diferentes.

En la advertencia preliminar de El viejo soldado (novela publicada en 2002), el autor explica que la escribió, en España, en días en que sobrevivía por la ayuda del amor familiar y de la solidaridad fraterna, cuando entre la insensatez y la confusión había creído perder su país para siempre, por lo que el impulso para la escritura "estuvo compuesto por la nostalgia y el furor" (Tizón, 2002a, p. 9).

La caracterización que Said (2005) realiza sobre el exiliado en Reflexiones sobre el exilio resulta adecuada para comprender cabalmente la actitud del artista desterrado, particularmente el del siglo XX. Los exiliados son "siempre excéntricos que sienten su diferencia (aun cuando la exploten con frecuencia) como una especie de orfandad” (p. 109). Así la diferencia deviene un arma a la que se aferra para seguir siendo él mismo y se expresa en la intransigencia ante lo que se le aparece como novedad y en la negación a ser aceptado en la nueva comunidad que lo ha recibido

El viejo soldado representa, en alguna medida, no los hechos como tales, sino la experiencia intensa del destierro. El protagonista sobrevive en Madrid sufriendo su condición de exiliado, ${ }^{19}$ sin lograr apegarse a nada en ese nuevo ámbito. Raúl siente que:

Las huellas de los pasos comenzaban a borrarse: los recuerdos seguían presentes, pero ya tenían una cierta distancia y alguna vaguedad, aunque muchas veces surgieran algunos, tenaces y deslumbrantes, para recordarle que el pasado no estaba muerto, sino escondido. (2002a, p. 23-24)

La experiencia traumática para Héctor Tizón está plasmada, como estamos exponiendo, en las memorias autobiográficas de No es posible callar, especialmente cuando cuenta que conoció en España al autor rumano, quien le obsequió un ejemplar de su novela:

Era, o es, una autobiografía supuesta de Ovidio, desterrado por el emperador Augusto en los extremos del imperio, y el libro comienza con esta frase: "Cierro los ojos para vivir".

19. Said (2005) plantea la experiencia del exilio individual como diferente de los nacionalismos de grupos: "el exilio tiene un sentido muy marcado de experiencia solitaria fuera del grupo: las privaciones sentidas por no estar con los demás en el lugar común en que se vive" (p. 105). Y más adelante concluye sobre el padecimiento del exiliado individual: "Está el puro hecho del aislamiento y el desplazamiento, que produce un tipo de masoquismo narcisista que se resiste a todos los esfuerzos de mejora y aculturación y a formar parte de la comunidad. En este extremo el exiliado puede convertir el exilio en un fetiche, una práctica que lo distancia de todas las relaciones y compromisos" (p. 110). 
Esas palabras fueron como un impacto para mi ánimo, como una síntesis y, tal vez, como un propósito o como una profesión de fe.

Cerraba los ojos para vivir. Nada de lo de afuera, ni los paisajes ni las cosas ni la gente, podría perturbar el mundo, tampoco la tierra que había dejado atrás, de la cual me arrojaran por un impulso injusto e inaceptable. (2004c, p. 122)

La negación a adaptarse, en los primeros tiempos de exilio, a ese nuevo ámbito extranjero en el que se había refugiado, para no perder su memoria, no cortar los lazos con su lugar de pertenencia, es una actitud que conservará en gran medida en sus años de desarraigo en España.

Asimismo, en "Ahora cerraremos los ojos cuando nos dé la gana”, cita en inglés el último verso del Ulysses de Alfred Lord Tennyson, después de mencionar al autor y de glosar en español el sentido del texto (p. 123), para precisar la manera de ser que iban asumiendo en el destierro, después de "maldigerir el dolor", con todas las pérdidas:

éramos los que aún éramos o, en rigor, lo que debíamos ser: un temple igual, debilitado por el extrañamiento y la desdicha, pero en todo caso tendríamos que ser, como en el poema de Tennyson, fuertes de ánimo para aspirar, buscar, hallar y no ceder:

To strive, to seek, to find, and not to yield. (2004c, p. 122-123)

Es justamente el poema de Tennyson que muestra un Odiseo heroico y con deseos de luchar y viajar, como el Ulises de Dante Alighieri. Si uno no ha tenido presente el Ulysses de Tennyson al comienzo, al leer la cita y encontrar esta relación puede comprender que, desde el principio del artículo, Tizón ha estado parafraseando ese texto del siglo XIX y dialogando con él desde su perspectiva actual. Incluso, por las alusiones a Homero y a Dante (Infierno, XXVI), indirectamente dialoga con ellos sobre la necesidad, humana y heroica a la vez, de resistir los dolores y dificultades y emprender la búsqueda de nuevos mundos.

W. B. Stanford (2013) incluyó el Ulysses de A. L. Tennyson en una de las líneas que la tradición ha construido en la reflexión y creación sobre el héroe homérico; es la iniciada por Dante en la Divina Comedia. La complejidad del carácter del héroe dio lugar a la oposición entre la concepción homérica y la de muchos otros escritores posteriores que abordaron el tema de Ulises:

El movimiento en la Odisea es básicamente hacia dentro, hacia la casa, hacia la normalidad. Según la concepción de poetas más tardíos, como Dante, Tennyson y Pascoli, el impulso de Ulises es centrífugo, hacia fuera, en dirección a lo exótico y anormal. (Stanford, 2013, p. 76)

Cuando se detiene a analizarlo ${ }^{20}$ opina que es "un poema de talantes notablemente variados", un monólogo lírico donde Ulises "habla con cinco voces distintas", a las cuales reconoce, con método de comparatista, por citas directas y alusiones:

20. Stanford menciona este poema en varios pasajes del libro, cuando lo compara a Tennyson con otros autores, pero en el capítulo "XIV. El viajero errante" dedica a su análisis algunas páginas (2013, p. 246-249). 
Son éstas las voces del Odiseo de Homero, del Ulises de Dante, del Ulises de Shakespeare, del Childe Harold de Byron y del Grenville del propio Tennyson. Sin embargo hay unificación en el efecto de conjunto, y lo que emerge al final es una figura que se reconoce, aunque desconcertada, como heroica, una contribución permanente e influyente al mito de Ulises. (Stanford, 2013, p. 246)

En el texto de Tizón que nos ocupa, la reflexión sobre el viaje odiseico está filtrada por la lectura del poeta inglés victoriano. Así se comprende el pensamiento que atribuye a Ulises al comienzo de este artículo que trata sobre el exilio y sobre la resistencia: "Pienso, como Ulises, que sólo soy una parte de mi propia historia, y que tal vez sean más que yo mismo los demás, los lugares y las cosas" (2004c, p. 121).

La idea tennisoniana señala que todo lo que se ha conocido en el viaje constituye a la persona, pero que hay mucho más que permanece desconocido, que incita a buscar y que se va ampliando a medida que más se conoce. Tizón retoma el contenido del famoso poema con el recuerdo de que la vivencia del destierro había sido decisiva en la conformación de quién era y es; no obstante, desde la distancia en que lo ubica el transcurso de los años, se permite abrirse y atisbar que son muchos otros conocimientos del mundo y experiencias de vida y de relaciones humanas los que conforman su ser.

También parte del poema de Tennyson la mención de Telémaco, aunque las circunstancias de Tizón y su familia en aquel tiempo hayan sido muy diferentes para pensar, como Ulises, en el relevo generacional en la conducción de los asuntos públicos.

Luego nuestro autor repasa la actitud negacionista del exiliado frente a la nueva realidad que se le había impuesto, rememorando el impacto que le produjo la lectura de Dios nació en el exilio de Vintila Horia y especialmente la total identificación con la frase inicial "Cierro los ojos para vivir".

Finalmente, advierte que ya no habrían sido los mismos después del tiempo de penuria y nostalgia, y se afirma en el reconocimiento de que eran lo que eran o lo que debían ser.

E1 Ulises de Tennyson está imbuido de la visión romántica de la vida intensamente vivida y de la entrega al espíritu del viaje como una búsqueda insaciable. A pesar de ello reconoce la pérdida del vigor de antaño en él y sus compañeros, pero se fortalece a partir de esa realidad presente: "that which we are, we are; / One equal temper of heroic hearts" ${ }^{21}$ y luego se afirma en la voluntad para emprender nuevos desafíos:

Made weak by time and fate, but strong in will

To strive, to seek, to find, and not to yield. ${ }^{22}$

Tizón parafrasea las últimas palabras de Ulises y se sostiene en la resistencia, tal como hemos señalado y citado más arriba, para vislumbrar una esperanza de regreso al "país arrasado", a diferencia

21. "lo que somos, somos: / un espíritu ecuánime de corazones heroicos"(p. 67-68; traducción de Randolph D. Pope). Cf. texto original en inglés "Ulysses”, editado por Ch. Ricks (2014, 138-145).

22. "debilitados por el tiempo y el destino, pero con una voluntad decidida / a combatir, buscar, encontrar y no ceder" (p. 69-70; traducción de Randolph D. Pope). 
del héroe al que dejamos, en el cierre del poema, a punto de emprender el viaje hacia nuevos mundos desconocidos.

Retoma el tópico en El resplandor de la hoguera (2008). En la introducción al libro, titulada "Narrar la propia vida", habla de "marchar al exilio" y de la sensación de "despojo y pertenencia". Nuevamente, la vuelta completa aportada por la noción de periplo es la que condensa el itinerario recorrido: "y ese lugar que nos vio nacer es también el que nos verá desaparecer cuando el hechizo de vivir se eclipse. De él venimos y hacia él marchamos como Ulises al cabo de sus periplos”(2008, p. 15).

Como ya hemos señalado, la experiencia de vida particular que significó el dejar su casa y su ambiente repercutió en su creación literaria, de manera distintiva, en la insistencia de las escenas de partida en sus relatos.

No obstante, en sus primeras novelas, ya se manifestaba el apego a la tierra de los padres como una señal identitaria, tal como quedó expresado en el pensamiento del Comisionado poco antes del final de El cantar del profeta y el bandido (1972):

Pero, quien se mueve de su patria pierde la voz, pierde el color de los ojos, ya no se llama igual. Y aunque logre afortunarse tampoco ya es el mismo, tiene otro color de piel y de noche y aun de día sueña siempre un mismo sueño que le está recordando una cosa dulce y perdida. (1982, p. 153)

Esta caracterización del que emigra de su tierra, con el acento puesto en el problema de la identidad, que lo acerca a la actitud ovidiana, se profundizó en sus novelas signadas por el exilio.

La ajenidad en el nuevo país y la angustia de la pérdida, la vivencia del vacío y del sinsentido existencial son rasgos muy marcados, sobre todo, en el carácter y en la conducta del protagonista de El viejo soldado.

\section{Conclusión}

Como ya argumentamos, las producciones donde se apropia de los tópicos clásicos sobre el sufrimiento del desterrado, remitiéndonos a una larga tradición que tuvo su inicio en la Antigüedad griega, son las memorias y artículos que hemos analizado en el presente trabajo.

Esos textos de carácter autobiográfico se sitúan en una tercera etapa de su trayectoria literaria. Una vez de regreso a su tierra natal y después de la superación del duelo de la pérdida, se abrió el camino para encontrar una identidad renovada, a partir de la cual surgieron nuevos proyectos de escritura.

En el diálogo con Ovidio, mediado por Vintila Horia, y con Ulises, mediado en esta instancia por A. L. Tennyson, la imagen "Cerraba los ojos para vivir", representativa del desterrado doliente, revela que su apropiación creativa en la escritura de Héctor Tizón es parte de un proceso de autorreconocimiento, por inmersión en el interior de sí mismo y por el recuento del pasado y de su producción anterior, para encontrarse allí con aquello que lo identifica y con los lugares propios de su literatura. 


\section{Referencias bibliográficas}

Florio, R. (1996). De Virgilio a Sábato: trasiego de catábasis. En Florio, R. (comp.), Tradición clásica y literaturas contemporáneas (pp. 33-46). Bahía Blanca, EdiUNS.

Friera, S. (2 de mayo de 2002). Cerrar los ojos para vivir. Página 12. https://bit.ly/2RkbALd.

Genette, G. (1989). Palimpsestos. La literatura en segundo grado. Taurus, Madrid.

Gramuglio, M. T. (2014). El realismo y sus destiempos en la literatura argentina. En Jitrik, N. (dir. de colección) y Gramuglio, M. T. (dir. del tomo), Historia Critica de la Literatura Argentina. El imperio realista (tomo 6, pp. 15-38). Buenos Aires, Emecé. (Original publicado en 2002.)

Guillén, C. (1998). Múltiples moradas. Ensayo de Literatura Comparada. Barcelona, Tusquets.

Hardwick, L. (2003). Reception Studies. Oxford-New York, Oxford University Press.

Homer (1953). The Odyssey. 2 vol (A. T. Murray, ed.). Cambridge, Harvard University Press/ London, William Heinemann.

Horia, V. (1961). Dios nació en el exilio. Buenos Aires, Emecé. (Original publicado en 1960.)

Martindale, Ch. (2007). Reception. En Kallendorf, C. W. (ed.), A Companion to the Classical tradition (pp. 297-311). Oxford, Blackwell.

Massei, A. P. (1998). Héctor Tizón. Una escritura desde el margen. Córdoba, Alción.

Ovidio (2010). Tristezas - Pónticas. Madrid, Akal.

P. Ovidius Naso (1939). Tristia. Wheeler, A. (ed.). Cambridge, Harvard University Press. Consultado en: http://www.perseus.tufts.edu.

Pacheco, C. (1992). La comarca oral. La ficcionalización de la oralidad cultural en la narrativa latinoamericana contemporánea. Caracas, La Casa de Bello.

Pacheco, C. (1996). La voz en la letra: sobre la construcción de la oralidad en la ficción latinoamericana. Versión 6, 151-175.

Perry, T. P. J. (2010). Exile in Homeric Epic. Graduate Department of Classics, University of Toronto.

Said, E. (2005). Reflexiones sobre el exilio (R. García Pérez, trad.). Barcelona, Debate. (Original publicado en 2001.)

Sarlo, B. (2007). Lejos de todo. En Escritos sobre literatura argentina (pp. 427-430), Buenos Aires, Siglo XXI. (Original publicado en 1997.)

Sarlo, B. (2014). Política, ideología y figuración literaria. En Balderston, D. et al, Ficción y política. La narrativa argentina durante el proceso militar (pp.53-89). Buenos Aires, Eudeba. (Original publicado en 1987.)

Stanford, W. B. (1968). The Ulysses Theme. The University of Michigan Press. 
Stanford, W. B. (2013). El tema de Ulises. (A. Silván, ed.; B. Afton Beattie y A. Silván, trads.). Madrid, Dykinson. (Original publicado en 1954.)

Tarja (1989a). Reproducción facsimilar en dos volúmenes. San Salvador de Jujuy, Universidad Nacional de Jujuy, I, 1-8.

Tarja (1989b). Reproducción facsimilar en dos volúmenes. San Salvador de Jujuy, Universidad Nacional de Jujuy, II, 9-16.

Tennyson, A. L. (2014). Ulysses. En Ricks, Ch. (ed.), Tennyson. A Selected Edition (pp.138-145). Oxford, Routledge. (Original de 1969.)

Tizón, H. (1982). El cantar del profeta y el bandido. Buenos Aires, Centro Editor de América Latina. (Original de 1972.)

Tizón, H. (1988). El hombre que llegó a un pueblo. Buenos Aires, Legasa.

Tizón, H. (1992). Extraño y pálido fulgor. Buenos Aires, Alfaguara.

Tizón, H. (2000). Fuego en Casabindo. Buenos Aires, Alfaguara. (Original publicado en 1969.)

Tizón, H. (2001). La casa y el viento. Buenos Aires, Alfaguara. (Original publicado en 1984.)

Tizón, H. (2002a). El viejo soldado. Buenos Aires, Alfaguara.

Tizón, H. (2002b). Luz de las crueles provincias. Buenos Aires, Alfaguara. (Original publicado en 1995.)

Tizón, H. (2004a). La belleza del mundo. Buenos Aires, Seix Barral.

Tizón, H. (2004b). La mujer de Strasser. Buenos Aires, Seix Barral. (Original publicado en 1997.)

Tizón, H. (2004c). No es posible callar. Buenos Aires, Taurus.

Tizón, H. (2008). El resplandor de la hoguera. Buenos Aires, Alfaguara.

Tizón, H. (2012). Memorial de la Puna. Buenos Aires, Alfaguara.

Whitmarsh, T. (2001). 'Greece is the World': exile and identity in the Second Sophistic. En Goldhill, S. (ed.), Being Greek under Rome. Cultural Identity, the Second Sophistic and the Dervelopment of Empire (pp. 269-305). Cambridge, University Press.

Zecchin de Fasano, G. C. (2008). Exilio y fuga: resonancias de Odisea en Borges y Bioy Casares. En Minellono, M. (comp.), La distorsión del espejo. Estrategias de la representación en textos de Literatura Argentina y Comparadas (pp. 337-350). La Plata, Al Margen. 
*Alejandra Liñán es Doctora en Letras, Profesora Titular de Lengua y Cultura Griegas y Adjunta de Seminario de Cultura Clásica en la Facultad de Humanidades de la Universidad Nacional del Nordeste (Argentina). Vicepresidenta de la Asociación Argentina de Estudios Clásicos. Sus áreas de investigación son: análisis filológico y literario de la literatura griega antigua; recepción de clásicos grecolatinos en la literatura contemporánea (especialmente argentina); y literatura comparada. Actualmente dirige el Grupo de estudios helénicos y de la tradición clásica y sus proyecciones, el cual lleva adelante la investigación: Las representaciones del Otro en el relato del viaje en textos de la Antigüedad tardia: Pseudo Calístenes y Nono de Panópolis, PI 18H003, acreditado en Secretaría General de Ciencia y Técnica de la UNNE.

RECIBIDO: 23/04/2021

ACEPTADO: 15/05/2021 